\title{
Effect of laboratory aging on chemistry and rheology of crumb rubber modified bitumen
}

\author{
Haopeng Wang (D) Xueyan Liu • Panos Apostolidis • Martin van de Ven • \\ Sandra Erkens $\cdot$ Athanasios Skarpas
}

Received: 17 October 2019/Accepted: 5 February 2020/Published online: 20 February 2020

(C) The Author(s) 2020

\begin{abstract}
Aging during construction and in-service substantially changes the chemical composition and physical properties of bitumen thereof influences the performance of asphalt pavements. The modification of bitumen by crumb rubber modifier (CRM) significantly increases the complexity of the aging mechanism and is expected to improve the aging resistance of bitumen. This study aims to investigate the effects of laboratory short-term and long-term aging on the chemistry and rheology of crumb rubber modified bitumen (CRMB). Neat bitumen and CRMB with four different CRM contents were studied. Fourier transform infrared spectroscopy and dynamic shear rheometer were employed to measure the change in the chemical composition and rheological properties of binders at different aging states. Bitumen hardening, which was rheologically revealed by the frequency sweep and multiple creep recovery test results, was also reflected in the growth of carbonyl and sulfoxide functional groups. In addition, the
\end{abstract}

H. Wang $(\bowtie) \cdot$ X. Liu $\cdot$ P. Apostolidis .

M. van de Ven · S. Erkens · A. Skarpas

Section of Pavement Engineering,

Faculty of Civil Engineering and Geosciences,

Delft University of Technology, Delft, The Netherlands

e-mail: haopeng.wang@tudelft.nl

A. Skarpas

Department of Civil Infrastructure and Environmental Engineering, Khalifa University, Abu Dhabi, United Arab Emirates aliphaticity and aromaticity indices of binders before and after aging were also investigated. CRMB binders showed improved aging resistance compared to neat bitumen as reflected by the decreased carbonyl and sulfoxide indices as well as the lower change in rheological parameters. Higher resistance against aging was achieved when increasing the CRM content. The results also highlight the correlation between chemistry and rheology of bitumen. Among six selected mechanical parameters of binder, the nonrecoverable creep compliance and percent recovery show better correlations with the combined chemical aging index (sum of carbonyl and sulfoxide indices) than the parameters derived from the linear viscoelastic region.

Keywords Crumb rubber modified bitumen . Aging · Oxidation - Chemical composition · Rheological property

\section{Introduction}

Bitumen, as a refined residue from the distillation process of crude oils, is composed of an extremely large number of different organic molecules, which makes it susceptible to the changes of environmental conditions [1]. The aging of bitumen affects nearly all critical aspects of asphalt paving materials, which makes aging a fundamentally important factor that 
influences the performance and durability of asphalt pavements. Aging of bitumen takes place in two stages, short-term aging during the mixing, transport and paving process, and long-term aging during the inservice period of asphalt pavement in the field [2]. Short-term aging of bitumen is primarily associated with the loss of volatile components and fast oxidation at high temperatures while long-term aging is more related to the progressive oxidation, steric hardening and ultraviolet radiation [3]. Among all, oxidation is regarded as the most important and best-understood aging process of bitumen.

Oxidative aging changes both chemical composition and physical properties of bitumen. Based on the polarity, bitumen can be separated into four fractions: saturates, aromatics, resins and asphaltenes, of which asphaltenes are the most polar. Each fraction is a continuum of molecules with varying molecular sizes, aromatic contents and polarity [4]. More reactive molecules with high polarity are more susceptible to oxygen. The types of oxidation products, mainly sulfoxides and ketones are consistently the same for bitumen from different sources [5]. Therefore, the corresponding carbonyl and sulfoxide functional groups [6], as characterized by infrared spectroscopy, have long been used to indicate the aging level of bitumen. During aging, the reaction of bitumen and atmospheric oxygen leads to the transformations of its generic fractions to more polar components, and increases in the number of large molecules, molecular weight and polydispersity. Specifically, part of the aromatic fraction of bitumen transforms into the resins, which in turn transforms into asphaltenes. On the other hand, the concentration of saturates does not change significantly due to their low reactivity $[4,5]$. The changes of bitumen chemistry after aging significantly influence the physical and rheological characteristics of bitumen. Aging causes stiffening of bitumen with reduced molecular flow, which can be verified by the increase in viscosity and complex modulus and decrease in phase angle [7, 8]. The stiffening effect increases the permanent deformation resistance, but reduces the relaxation capacity under environmental and traffic loadings resulting in performance deterioration of asphalt pavements $[9,10]$.

Crumb rubber modification of bitumen has become common practice in the asphalt paving industry due to its improved physical properties and environmental benefits [11]. For crumb rubber modified bitumen
(CRMB), aging is also an inevitable process and plays a critical role in determining the in-service performance of rubberized pavement. However, compared to neat bitumen, the aging mechanism for CRMB is much more complex because of the interaction between crumb rubber modifier (CRM) and bitumen and the unique chemical compositions of CRM. Two parallel reactions were reported during the aging process of CRMB: the aging of the bitumen phase and the degradation of included rubber particles [12]. During the preparation of a bitumen-rubber blend, crumb rubber particles absorb the low-molecularweight fractions of bitumen (part of the maltenes) because of the thermodynamic compatibility and swell up to several times their original sizes at elevated temperatures. When subjected to more severe interaction conditions (i.e., higher temperatures and extended time), the dissolution of rubber into bitumen takes place $[13,14]$. The bitumen-rubber interaction changes not only the component fractions and microstructure of bitumen but also the nature of CRM. The absorption of maltenes and swelling of CRM particles together contributes to the stiffening of CRMB binder [15]. This change also definitely influences the aging mechanisms and reaction kinetics of CRMB. Moreover, the unique and complex compositions of CRM affect the ageing process of bitumen individually. CRM generally consists of rubber polymer, carbon black and various processing agents which include antioxidants/antiozonants and curing additives (sulfur, zinc oxide, stearic acid, accelerator and oil etc.). Previous studies have shown that CRM particles can release their components into bitumen in different ways given the different interaction conditions [16, 17]. The component exchange between bitumen and CRM alters the aging process and physical properties of CRMB binder. The released polymeric chains from the rubber network function as retardants in bitumen during aging. They can hinder the penetration of oxygen molecules into the bitumen and reduce the oxidation rate of the bitumen phase itself. Besides, from the mechanical point of view, polymer degradation from chain scission during aging, which is detrimental to the mechanical properties of the binder, partly offset the age hardening of bitumen components [18]. It was also reported that the addition of carbon black into bitumen increases its aging resistance [19]. Antioxidants, which are added to protect rubber particles from oxidation, can also retard 
the reactive groups of bitumen and protect them against the attack of oxygen [20]. In summary, the crumb rubber modification of bitumen significantly increases the complexity of aging mechanism and is expected to improve the aging resistance of bitumen.

\section{Objective and approach}

This study aims to investigate the effects of laboratory short-term and long-term aging on the chemistry and rheology of crumb rubber modified bitumen. Fourier transform infrared spectroscopy (FTIR) and dynamic shear rheometer (DSR) were employed to detect possible changes in the chemical composition and rheological properties of binders at different aging states. FTIR was used to characterize the changes of chemical functional groups of the binder. Both frequency sweep tests and multiple stress creep and recovery tests were performed to obtain the rheological parameters of the binder in the linear viscoelastic and nonlinear viscoelastic regions. First, an alternative short-term aging procedure (oven aging) was proposed for CRMB due to the problems with the traditional aging method (i.e., rolling thin film oven test). Then, the effect of CRM concentrations on the aging performance of bitumen was examined.

\section{Materials and methods}

\subsection{Materials and binder preparation}

Penetration grade 70/100 bitumen (Nynas) commonly used in the Netherlands was used as the base bitumen in this study. The base bitumen is graded as PG 64-22 according to the Superpave specification. The SARA (saturates, aromatics, resins and asphaltenes) fractions of the base bitumen are $7 \%, 51 \%, 22 \%$, and $20 \%$ respectively (Iatroscan TLC-FID). The CRMs ground from waste truck tires at ambient temperatures have an irregular shape and particle sizes ranging from 0 to $0.5 \mathrm{~mm}$ (nominal maximum particle size). The basic properties, composition and particle gradation of CRM are shown in Table 1. The processing agents mainly consist of antioxidants/antiozonants and curing additives (e.g., sulfur, zinc oxide, stearic acid, accelerator and oil etc.).
The CRMB binders were produced in the laboratory by blending different percentages of CRMs with the base bitumen. Four CRM contents including 5\%, $10 \%, 15 \%$ and $22 \%$ by mass of base bitumen were used. These CRMBs were labelled as CRMB-5, CRMB-10, CRMB-15 and CRMB-22. Manual stirring for 5 min was applied to pre-distribute CRMs into base bitumen, then the blend was mixed using a Silverson high shear mixer with a square hole screen at $180{ }^{\circ} \mathrm{C}$ with the shearing speed of $6000 \mathrm{rpm}$ for $30 \mathrm{~min}$. This mixing condition was optimized based on the criteria to obtain better mechanical properties of CRMB [21]. During the laboratory mixing process, the mixing head was immersed into the hot bitumen to avoid vortex which may potentially cause oxygen ageing.

\subsection{Aging procedure}

\subsubsection{Standard aging procedure}

Currently, the most commonly used laboratory aging methods for simulating the short-term (plant, transport and construction) aging and long-term (in-service) aging of bitumen are the rolling thin film oven (RTFO) test (ASTM D2872) and the pressure aging vessel (PAV) test (ASTM D6521), respectively [22]. In the RTFO aging procedure, $35 \mathrm{~g}$ of bitumen sample is poured into a specifically designed glass bottle which is later placed in a circular carriage in a strictly specified oven. The conditioning temperature of the oven is maintained at $163{ }^{\circ} \mathrm{C}$ for $85 \mathrm{~min}$. During the aging process, the bottles containing bitumen samples are rotated to allow binders to fully and uniformly coat the bottles to create a film thickness of about $1.25 \mathrm{~mm}$. In addition, fresh and hot air is periodically injected into the bottles to intensify the binder aging process. In the PAV aging procedure, $50 \mathrm{~g}$ of previously RTFO aged bitumen samples are collected and poured into a $140 \mathrm{~mm}$ diameter pan to create a film thickness of approximate $3.2 \mathrm{~mm}$. The prepared samples are further aged in a pressurized environment $(2.1 \pm 0.1 \mathrm{MPa})$ at an elevated temperature of $100{ }^{\circ} \mathrm{C}$ for $20 \mathrm{~h}$.

\subsubsection{Alternative short-term aging procedure}

While the RTFO aging procedure works well for unmodified binders, it encounters problems with 
Table 1 Basic properties and particle size distribution of CRM

\begin{tabular}{ll}
\hline Properties & Description or value \\
\hline Source & Scrap truck tyres \\
Colour & Black \\
Morphology & Porous \\
Specific gravity $\left(\mathrm{g} / \mathrm{cm}^{3}\right)$ & 1.15 \\
Decomposition temperature $\left({ }^{\circ} \mathrm{C}\right)$ & $\sim 200$ \\
Chemical composition & \\
Total rubber (natural and synthetic) & 55 \\
Carbon black $(\%)$ & 25 \\
Processing agents $(\%)$ & 20 \\
Gradation & \\
Sieves (mm) & Passing $(\%)$ \\
0.710 & 100 \\
0.500 & 93 \\
0.355 & 63 \\
0.180 & 21 \\
0.125 & 9 \\
0.063 & 2 \\
\hline
\end{tabular}

modified binders, especially highly viscous binders (e.g., some polymer modified bitumen and the CRMB in this study). Because of their high viscosity at the fixed temperature of $163{ }^{\circ} \mathrm{C}$, these modified binders do not flow properly inside the bottles to fully coat the bottle and may even roll out of the bottles [23]. In addition, highly viscous CRMB is difficult to scrape out of the RTFO bottle after the aging process. Given these issues, an alternative thin film oven aging method was proposed in an attempt to reach a similar aging level as the standard RTFO test.

The modified oven aging procedure is based on the thin-film oven test (ASTM D1754) where the hot bitumen is placed in $140 \mathrm{~mm}$ diameter pans on a shelf in an oven maintained at $163{ }^{\circ} \mathrm{C}$ for specific durations. However, the differences include (a) the static shelf is used instead of a rotating shelf; (b) the weight of hot bitumen is adjusted to be only 20 grams, so the binder film thickness is approximately the same as the one in the RTFO test $(\sim 1.25 \mathrm{~mm})$. Thus, the unknown factor making the modified oven aging comparable to the standard RTFO aging is the test duration. In this study, the base bitumen (Pen 70/100) was taken as the reference material since the RTFO tests were initially designed based on unmodified bitumen [3]. Bitumen Pen 70/100 samples was subjected to the modified oven aging procedure for $1 \mathrm{~h}, 2 \mathrm{~h}, 3 \mathrm{~h}$ and $4 \mathrm{~h}$ to simulate the short-term aging. After that, both modified oven-aged and RTFO-aged samples were compared by performing the FTIR and DSR tests (frequency sweep and MSCR) to determine which oven aging duration can give a comparable short-term aging effect as the standard RTFO aging procedure. Based on the results, the modified oven aging procedure was adopted to perform the short-term aging of CRMB binders. By treating the neat and CRMB binders under the same aging condition, the influence of CRM modification on the aging characteristics of binders can be compared. For the long-term aging procedure, the standard PAV test was applied on all short-term aged binders.

\subsection{Fourier transform infrared spectroscopy}

A Perkin Elmer Spectrum 100 FTIR spectrometer (PerkinElmer, Wellesley, Massachusetts) was used in the attenuated total reflectance (ATR) mode to acquire the infrared spectra for all the bitumen samples. The wavelength of the reflected beam is characteristic of each element and indicates the presence of specific chemical functional groups. Sample preparation is simple for the ATR technique. A small sample of material was taken using a spatula and placed on the top of the ATR crystal. The FTIR spectrum was obtained in the wavelength number range from 4000 to $600 \mathrm{~cm}^{-1}$ with a scanning resolution of $4 \mathrm{~cm}^{-1}$ averaging twenty scans for each measurement at ambient temperatures. For each type of material, five trials were performed at each aging condition for analysis. Quantitative analysis of the obtained spectra was carried out to identify the changes of functional groups of bitumen at different aging states.

The oxidation process can alter the chemical compositions of the bitumen by bonding bitumen molecular groups with atmospheric oxygen. Carbonyl compounds and sulfoxides are commonly formed during the chemical transformations caused by oxidative aging. Therefore, to quantitatively analyze the changes of specific functional groups due to the aging effects, the peak areas under the specific band were measured from valley to valley at specifically selected wavenumbers of the obtained spectrum [24].Two aging related indices, the carbonyl index $\left(I_{\mathrm{C}=\mathrm{O}}\right)$ and 
sulfoxide index $\left(I_{\mathrm{S}=\mathrm{O}}\right)$ are defined as Eqs. 1 and 2. In addition, the aliphaticity index $\left(I_{\mathrm{Al}}\right)$ and aromaticity index $\left(I_{\mathrm{Ar}}\right)$ were also calculated to monitor the evolution of chemical constituents of binder during aging [8].

$\mathrm{I}_{\mathrm{C}=\mathrm{O}}=\frac{A_{1700}}{\sum A}$

$\mathrm{I}_{\mathrm{S}=\mathrm{O}}=\frac{A_{1030}}{\sum A}$

$I_{\mathrm{Al}}=\frac{A_{1376}+A_{1460}}{\sum A}$

$\mathrm{I}_{A r}=\frac{A_{1600}}{\sum A}$

$\begin{aligned} \sum A= & A_{(2953,2862)}+A_{1700}+A_{1600}+A_{1460}+A_{1376} \\ & +A_{1030}+A_{864}+A_{814}+A_{743}+A_{724}\end{aligned}$

where $A$ represents the peak area under specific waveband and $\sum A$ is the sum of the total considered peak areas.

\subsection{Dynamic shear rheometer}

\subsubsection{Frequency sweep test}

A dynamic shear rheometer (Anton Paar) was utilized to obtain the rheological parameters (complex shear modulus and phase angle) of different binders following the standard test method. Frequency sweep tests were carried out with a parallel-plate geometry (25 mm diameter and $1 \mathrm{~mm}$ gap) from 0.1 to $100 \mathrm{rad} / \mathrm{s}$ at temperatures of $10,30,50$ and $70{ }^{\circ} \mathrm{C}$. Before the frequency sweep tests, strain amplitude sweep tests were conducted to identify the linear viscoelastic (LVE) range of different binders and thus to ensure the frequency sweep tests were undertaken within the binder's LVE region of response. The LVE limit was defined as the point where the complex shear modulus has decreased to $95 \%$ of its initial value [25]. Based on the LVE limits, all the measurements were carried out at a strain level of $0.1 \%$ in the straincontrolled mode.

In the present study, a modified ChristensenAnderson-Marasteanu (CAM) model (Eqs. 6 and 7) and Williams-Landel-Ferry (WLF) equation (Eq. 8) for shift factors fitting were used to develop complex modulus and phase angle master curves of the bitumen based on the frequency sweep test results [26].

$G^{*}=\frac{G_{g}^{*}}{\left[1+\left(f_{c} / f_{r}\right)^{k}\right]^{m / k}}$

where $G_{g}^{*}$ is the $G^{*}$ when the frequency approaches to infinity, often called glass complex modulus; $f_{c}$ is the crossover frequency; $f_{r}$ is the reduced frequency; and $k, m$ are the shape parameters, dimensionless.

$$
\delta=90 I-\frac{90 I-\delta_{m}}{\left\{1+\left[\frac{\log \left(f_{d} / f_{r}\right)}{R_{d}}\right]^{2}\right\}^{m_{d} / 2}}
$$

where $\delta_{m}$ is the phase-angle constant at $f_{d}$, the value at the inflexion point for binders; $f_{d}$ is the location parameter with a dimension of frequency, at which $\delta_{m}$ occurs; $R_{d}, m_{d}$ are the shape parameters; and for binders, $I=0$ if $f>f_{d}, I=1$ if $f \leq f_{d}$. The WilliamsLandel-Ferry (WLF) equation (Eq. 3) was used to obtain the shift factors.

$\log \alpha_{T}(T)=\frac{-C_{1}\left(T-T_{R}\right)}{C_{2}+\left(T-T_{R}\right)}$

where $C_{1}, C_{2}$ are the empirically determined constants; $T$ is the test temperature; $T_{\mathrm{R}}$ is the reference temperature; $\alpha_{T}(T)$ is the shifting factor.

The R-index defined in Eq. 9 is an indicator of the width of the relaxation spectrum [27]. A higher value is an indication of a more gradual transition from the elastic to viscous behaviour. It indicates less sensitivity to frequency changes, generally lower $G^{*}$ values, and higher phase angles within the intermediate range of frequency.

$R=\left(\frac{m}{k}\right) \log 2$

\subsubsection{Multiple stress creep and recovery test}

The MSCR test was conducted at two stress levels $(0.1 \mathrm{kPa}$ and $3.2 \mathrm{kPa})$ according to AASHTO M33218. The testing temperature was chosen at $64{ }^{\circ} \mathrm{C}$ based on the high temperature of binder PG 64-22. At each stress level, the test protocol consists of ten cycles of creep and recovery process. Each cycle includes a creep load of $1 \mathrm{~s}$ duration followed by $9 \mathrm{~s}$ recovery at 
zero loads. For each loading cycle the initial strain, maximum strain at the end of the loading, and strain at the end of the recovery portion were recorded. The non-recoverable creep compliance $\left(J_{\mathrm{nr}}\right)$ and the percentage of recovery were calculated based on the recorded strains to characterize the stress dependence and elastic response of bitumens. Three replicates were tested for each type of binder.

\section{Results and discussions}

\subsection{Determination of the oven aging duration}

Figure 1 shows the master curves of complex modulus and phase angle of the neat bitumen at different shortterm aging conditions. The reference temperature for the master curves was chosen as $30^{\circ} \mathrm{C}$. For the oven aged bitumen, the complex modulus increases while the phase angle decreases with the extension of aging time. The increased age hardening effect of bitumen was also observed in terms of the MSCR results in Table 2. Both frequency sweep and MSCR test results pointed out that bitumen aged in the oven at $163{ }^{\circ} \mathrm{C}$ for $2 \mathrm{~h}$ has similar rheological properties as the bitumen aged in the RTFOT. Therefore, based on the rheological parameters, the 2-hour static oven aging is comparable to the standard RTFO ageing and can be used as an alternative to RTFOT for simulating shortterm aging.

Since mechanical tests only give averaged properties of the bitumen sample, FTIR tests were also performed to compare the oxidation products that directly related to aging. Figure 2 shows the comparison of carbonyl and sulfoxide indices of the neat bitumen at different short-term aging states. It is clear that the oven aging with a duration of $2 \mathrm{~h}$ generated similar oxidation products as the standard RTFOT did. With the validation from both rheological and chemical properties of aged bitumen, it was decided to use the modified static oven aging for $2 \mathrm{~h}$ in replacement of the standard RTFO aging procedure for all the binders.

\subsection{FTIR analysis}

Aging causes chemical composition changes in bitumen. It is worthy to mention that there are no polybutadiene peaks at $965 \mathrm{~cm}^{-1}$ indicating the $=\mathrm{C}-$
$\mathrm{H}$ in phase out-of-plane bending of trans-1,4-butadiene observed for all the CRMB binders. Figure 3 presents the typical FTIR spectra of base bitumen and CRMB, in which no peaks at $965 \mathrm{~cm}^{-1}$ were detected for CRMB. This is because the ATR mode FTIR can only detect a very thin film of the bitumen sample about $2 \mu \mathrm{m}$ while the rubber particle size is too large to be detected [28].

Figure 4 shows the aliphaticity and aromaticity indices of binders at different aging states. The aliphatic structures usually exist in the light fractions of bitumen. During the aging process, light components of bitumen volatiles and aliphatic chains form aromatic rings. The reduction of aliphalticity with aging was observed for all binders in Fig. 4a. Due to the low reactivity of aliphatic compounds, the reduction of aliphaticity is not obvious on aging. It is also noteworthy that the aliphaticity index of unaged CRMB decreases with the increase of CRM content. This is because the rubber particles absorb the light fractions of bitumen during the interaction process. The absorption of light fractions may continue during aging, resulting in a decrease of the aliphaticity index. The aromaticity index denotes the aromatization of bitumen molecules. Two mechanisms including aromatization of perhydro aromatic rings and aromatization of alkyl substituted naphthenic rings take place during this process [29]. The aromaticity of neat bitumen increased after aging, which confirms that the formation of aromatics is associated with an equivalent reduction of the aliphatic structures. However, this is not the case for CRMB binders. In contrast, the aromaticity of all the CRMB binders first decreased at the short-term aging stage and then increased at the long-term aging stage. This finding is also consistent with previous studies [30]. This is possibly because CRM continued to interact with bitumen during the short-term aging through absorption of aromatics and swelling [31]. In addition, some aromatic rings fuse to produce more asphaltenes. At the long-term aging stage, rubber polymer degradation may happen and generate more aromatic hydrocarbons through the chain scission process. In addition, the processing oil containing aromatic components together with the earlier absorbed light fractions in rubber may be released from the rubber particles into bitumen. These mechanisms contribute to the increase of aromaticity during the long-term aging stage. 
Fig. 1 Complex modulus and phase angle master curves of the neat bitumen at different short-term aging conditions

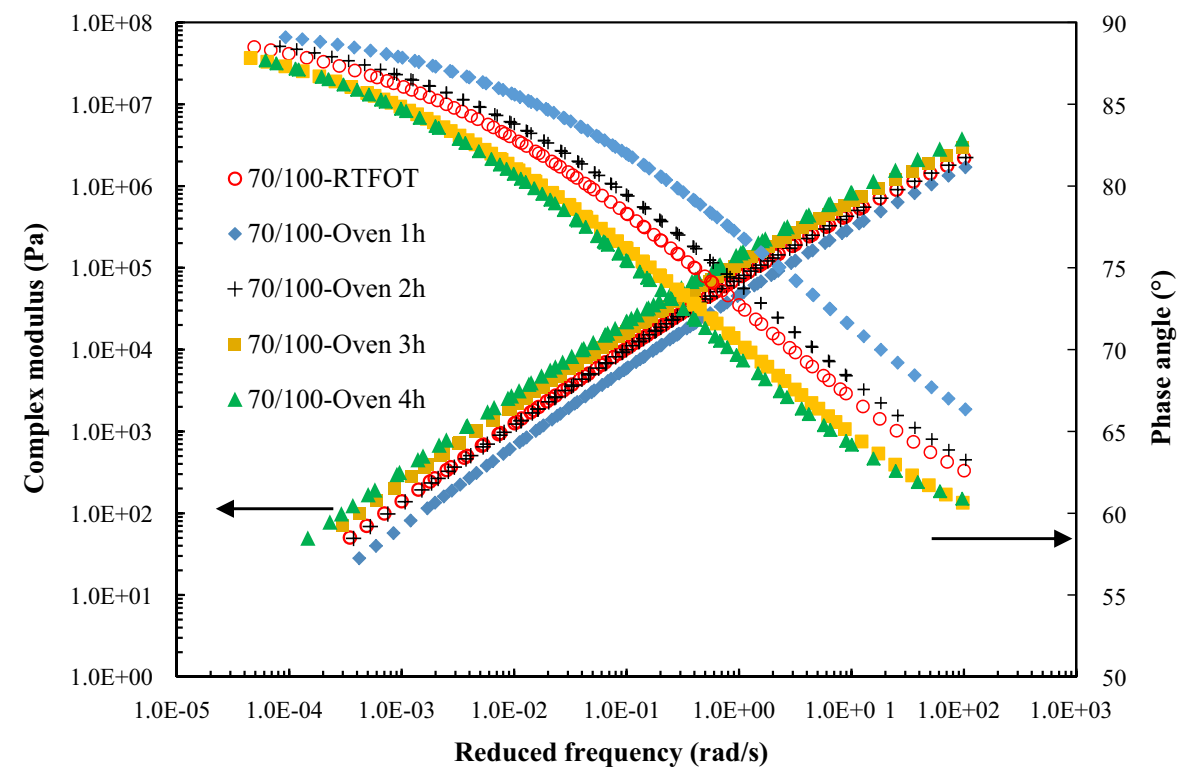

Table 2 MSCR results of the neat bitumen at different short-term aging conditions

Fig. 2 a Carbonyl index and $\mathbf{b}$ sulfoxide index of the neat bitumen at different short-term aging conditions

\begin{tabular}{llllll}
\hline Aging condition & \multicolumn{2}{l}{ Average recovery $(\%)$} & & \multicolumn{2}{l}{ Average $J_{\mathrm{nr}}(1 / \mathrm{kPa})$} \\
\cline { 2 - 3 } & $0.1 \mathrm{kPa}$ & & & $0.1 \mathrm{kPa}$ & $3.2 \mathrm{kPa}$ \\
\hline RTFOT & 1.40 & No recovery & & 3.90 & 4.44 \\
Oven $1 \mathrm{~h}$ & 0.09 & No recovery & & 5.59 & 6.22 \\
Oven $2 \mathrm{~h}$ & 1.55 & No recovery & & 3.49 & 3.94 \\
Oven $3 \mathrm{~h}$ & 4.74 & No recovery & & 2.61 & 3.07 \\
Oven $4 \mathrm{~h}$ & 6.75 & 0.29 & & 1.86 & 2.04 \\
\hline
\end{tabular}

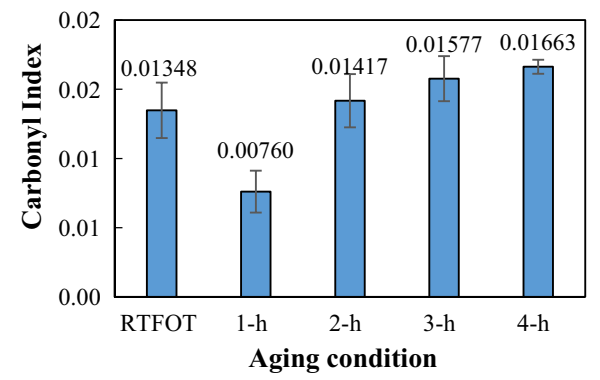

(a)

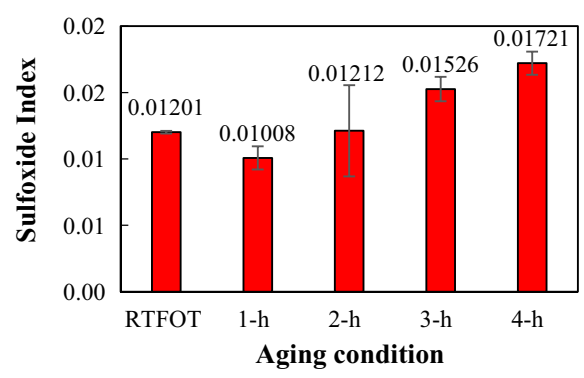

(b)
Ketones and sulfoxides are the main oxidation products of bitumen aging. The ketone functional group, the major component of the carbonyl absorption region in FTIR, is formed primarily from the oxidation of benzyl carbons in side chains attached to highly condensed aromatic ring systems. Sulfoxides are derived from the oxidation of sulfides. Figure 5 shows that the values of the carbonyl and sulfoxide indices consistently increase for all binders during aging. However, when increasing the CRM content of CRMB, the increase of both carbonyl and sulfoxide functional groups become less after aging, indicating decreased bitumen oxidation. The improvement of aging resistance due to crumb rubber modification can be attributed to three mechanisms. Firstly, light fractions of bitumen are absorbed by rubber particles, 


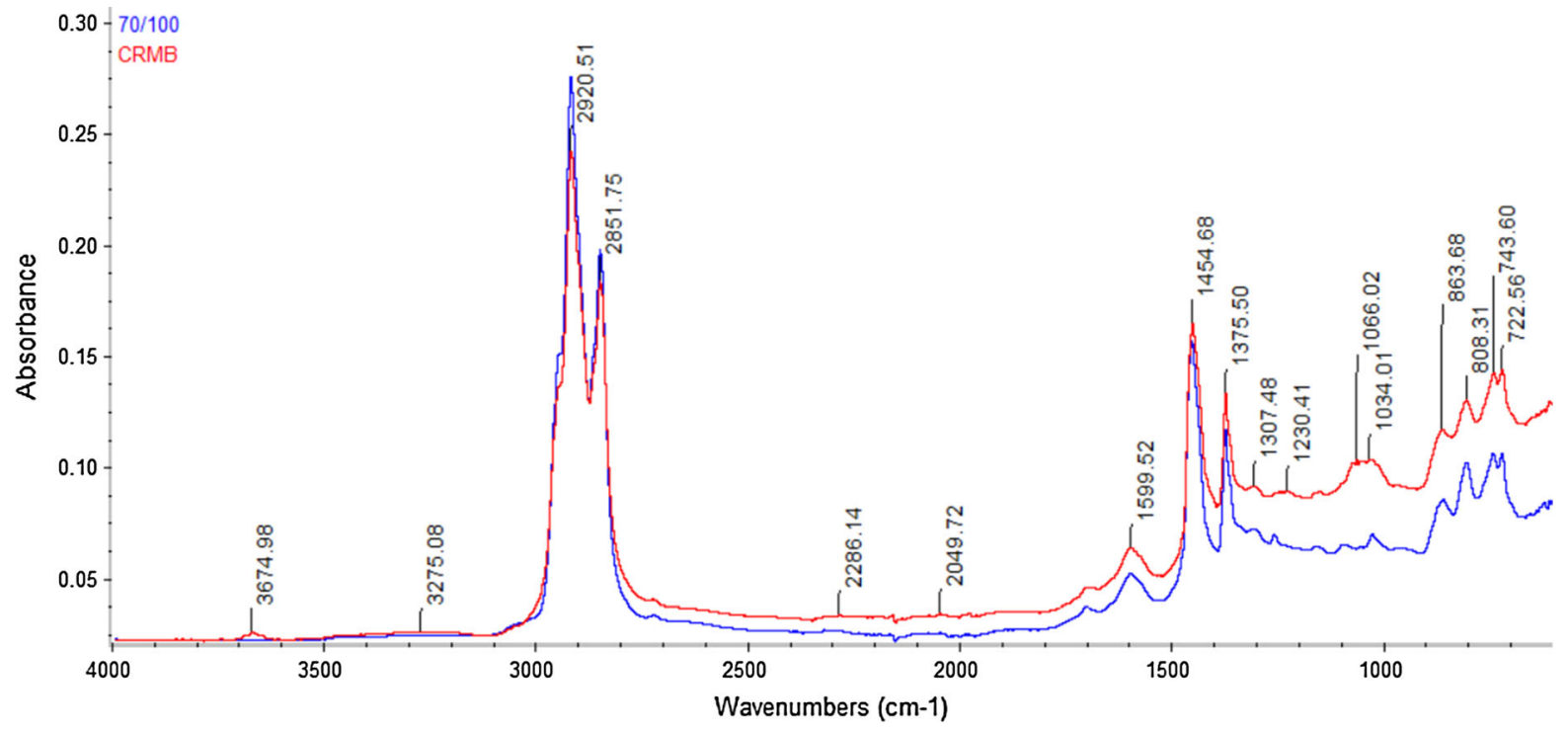

Fig. 3 FTIR spectra of base bitumen and CRMB

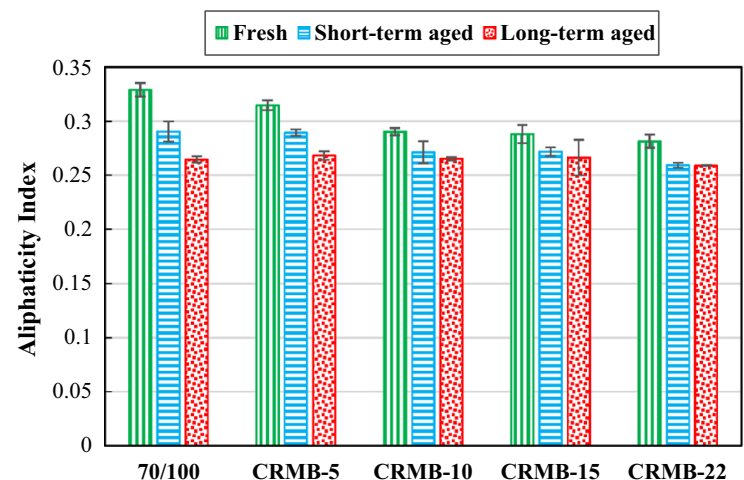

(a)

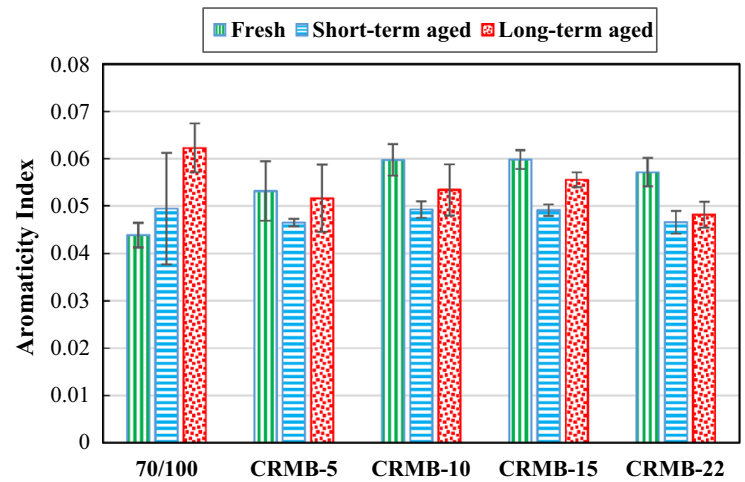

(b)

Fig. 4 a Aliphaticity index and $\mathbf{b}$ aromaticity index of binders at different aging conditions which means there are less reactive bitumen molecules available to be oxidized. In addition, these early absorbed low molecular weight constituents may be released into bitumen during the aging stage, compensating for the lost components due to aging. Furthermore, the presence of antioxidants in the oily component of crumb rubber retard the oxidation process. Thirdly, polymer chains from the rubber network can also function as retardants to hinder the penetration of oxygen molecules into bitumen. Under this circumstance, polymer chains are preferably attacked by oxygen, so the reaction of polar bitumen molecules with oxygen is delayed.

\subsection{Aging effects on the rheological properties of binders}

\subsubsection{Frequency sweep test}

Aging is known to alter the rheological properties of bitumen, causing an increase in complex modulus and a decrease in phase angle at certain frequencies. Figure 6 shows the complex modulus and phase angle master curves of neat bitumen and CRMB with different CRM contents in both fresh and aged states based on the CAM model. Generally, with the increase of aging extent (from short- to long-term), the complex modulus master curve shifts upwards while the phase angle master curve shifts downwards, which 
indicates stiffer and more elastic response of bitumen after aging. The gaps between the complex modulus master curves of different aging states become smaller with the addition of CRM into bitumen. When the CRM content reaches $22 \%$, the complex modulus master curves of fresh and aged CRMBs are almost overlapped, indicating less aging influence. The phase angle master curves of all CRMB binders show the characteristic plateau in the intermediate frequency domain. This unique feature represents the presence of polymer (rubber) in the bitumen. At high CRM contents of $15 \%$ and $22 \%$, the phase angle master curves of CRMBs in the fresh and aged states were interlaced, which shows the complexity of the chemical structure of (aged) CRMB. It is believed the degradation of rubber polymer and the oxidation of bitumen components take place simultaneously for high-content CRMB. The softening effect to the binder from polymer degradation compensates the stiffening effect from bitumen oxidation, as a result that the mechanical properties of CRMB binders vary

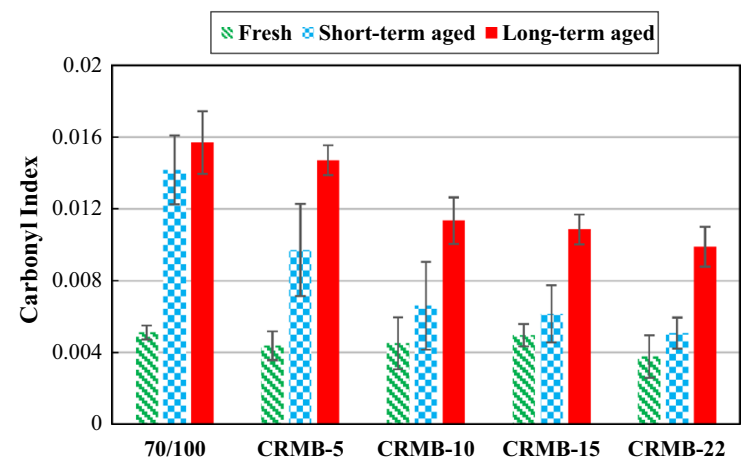

(a)

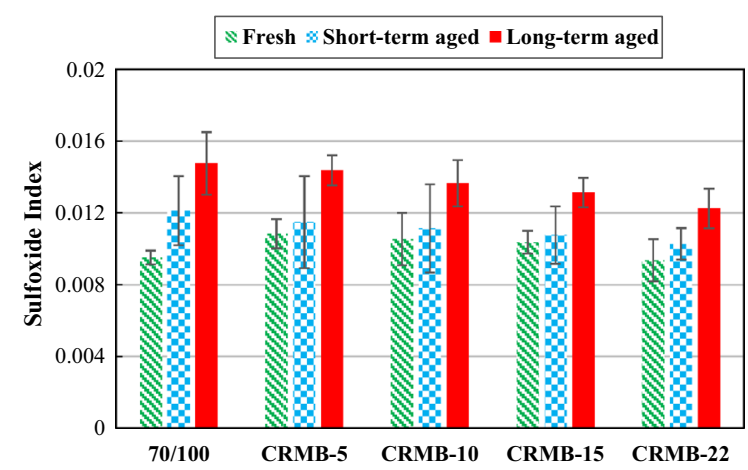

(b)

Fig. 5 a Carbonyl index and $\mathbf{b}$ sulfoxide index of binders at different aging conditions insignificantly after aging. Due to the inconsistency of complex modulus and phase angle over the frequency range at different aging states, it is unreasonable to define an aging index based on solely selected point values of complex modulus or phase angle at a certain frequency.

To further quantitatively characterize the aging effect, a series of parameters based on the rheological properties are summarized in Table 3. The crossover frequency and the rheological index $R$ (Eq. 9) were captured from the CAM model. The $R$-index is directly proportional to the width of the relaxation spectrum and is a measure of the shear rate dependency of bitumen [32]. In addition, the original Superpave rutting factor $\left(G^{*} / \sin \delta\right)$ at the high temperature of $64{ }^{\circ} \mathrm{C}$ (corresponding to the testing temperature of MSCR) and angular frequency of $10 \mathrm{rad} / \mathrm{s}$, as well as the G-R parameter $\left(G^{*} \cdot(\cos \delta)^{2} /\right.$ $\sin \delta$ ) at an intermediate temperature of $15^{\circ} \mathrm{C}$ and angular frequency of $0.005 \mathrm{rad} / \mathrm{s}$ were derived from the built master curves. The $\mathrm{G}-\mathrm{R}$ parameter is an indicator of the ductile behavior or brittleness, which can be used to assess the non-load associated cracking of binder [33].

For neat bitumen and CRMB-5, aging causes a decrease of the crossover frequency while it has insignificant influence on the crossover frequencies of other CRMB binders. For each binder, the $R$-index decreases after aging, meaning a smaller relaxation spectrum and increased sensitivity to frequency change. The aging causes the increase of the rutting factor for each binder. The G-R parameters of all the binders show an increasing trend with aging, which means the binders become more brittle and thus vulnerable to cracking. It is noteworthy that both short-term and long-term aging results in a gradual change of the $R$-index of binders, while long-term aging seems to have more severe impacts on the change of rutting factors and $\mathrm{G}-\mathrm{R}$ parameters than short-term aging does.

\subsubsection{MSCR test}

The MSCR test, which can capture the nonlinear viscoelastic properties of bitumen, was also employed to investigate the aging effect. It was found that MSCR test method is sensitive to the microstructure of polymer modified bitumen and used to determine the presence of elastic response. Therefore, it is 
Fig. 6 Complex modulus and phase angle master curves of a neat bitumen b CRMB-5 c CRMB-10 d CRMB-15 and e CRMB22 at different aging conditions

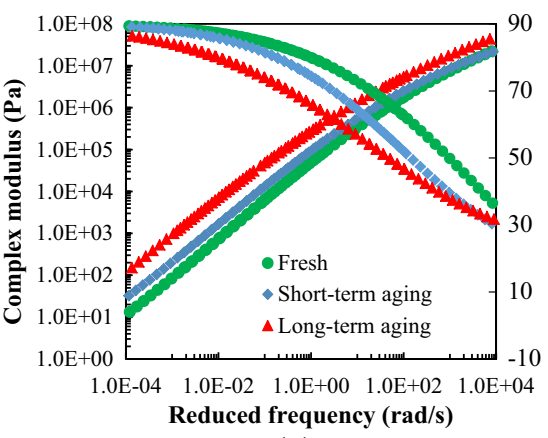

(a)

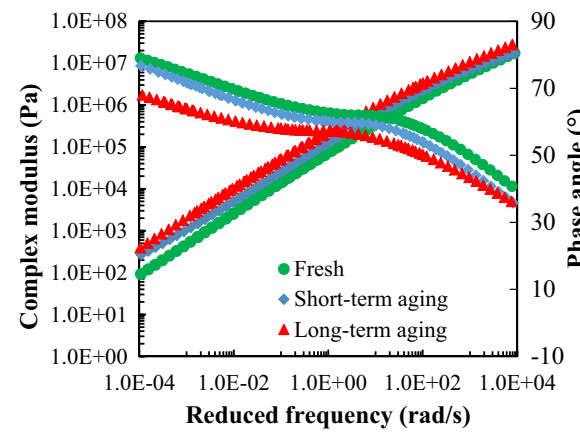

(c)

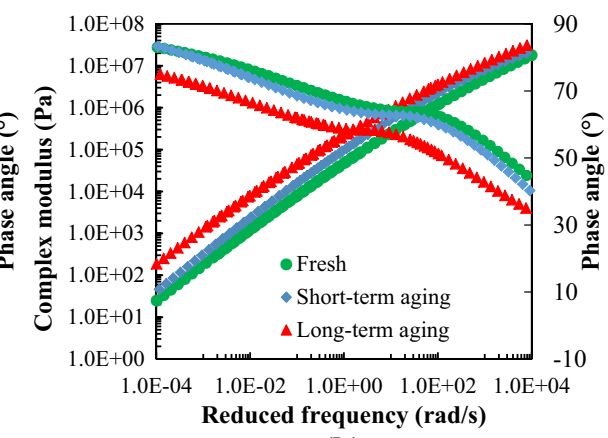

(b)

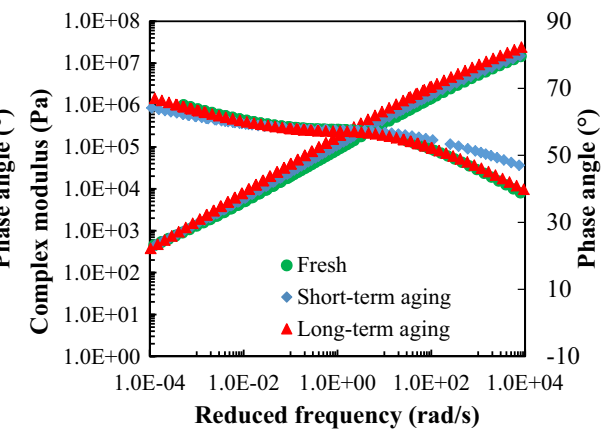

(d)

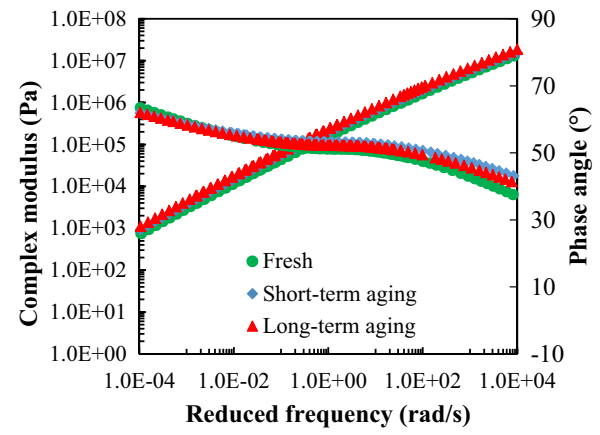

(e)

anticipated that the results can be used to more effectively characterize the microstructural changes of CRMB at different aging conditions. The average values of MSCR test results from three replicates for each binder at different aging states are summarized in Table 4.

It is clear that the crumb rubber modification of bitumen significantly decreases the non-recoverable creep compliance and increase the percent recovery of neat bitumen, which means improved resistance to permanent deformation. This improvement intensifies with increase of CRM content. The increase in percent recovery implies the increased elasticity of bitumen.
Regarding different binders, the aging process influenced the binder creep-recover property in different ways. In general, the aged binders show higher resistance to permanent deformation than the fresh binders, as evidenced by the smaller $J_{\mathrm{nr}}$ values and superior percent recover at all stress levels. To more directly investigate the aging effect on the binder, the following aging index (AI) based on the $J_{\mathrm{nr}}$ values at $3.2 \mathrm{kPa}$ stress level was defined (Eq. 10). A higher aging index indicates a higher degree of susceptibility towards aging effect and vice versa. 
Table 3 Fitted and derived parameters from the master curves of binders at different aging states

\begin{tabular}{llclcc}
\hline Sample code & Aging condition & Crossover frequency $(\mathrm{rad} / \mathrm{s})$ & $R$ index & $G^{*} / \sin \delta(\mathrm{kPa})$ & $\mathrm{G}-\mathrm{R}$ parameter $(\mathrm{kPa})$ \\
\hline $70 / 100$ & Unaged & 1844.93 & 1.44 & 1.65 & 0.19 \\
& Short-term aged & 395.51 & 1.36 & 2.85 & 0.74 \\
& Long-term aged & 70.63 & 1.32 & 7.76 & 12.76 \\
CRMB-5 & 1847.22 & 3.22 & 2.77 & 1.96 \\
& Unaged & 488.80 & 3.05 & 3.14 & 6.43 \\
& Short-term aged & 2.91 & 9.05 & 37.90 \\
CRMB-10 & Long-term aged & 284.84 & 3.61 & 4.85 & 8.71 \\
& Unaged & 580.49 & 1.94 & 7.60 & 14.51 \\
& Short-term aged & 580.17 & 1.77 & 13.79 & 48.36 \\
CRMB-15 & Long-term aged & 580.88 & 5.27 & 9.00 & 13.05 \\
& Unaged & 800.00 & 3.67 & 10.23 & 16.82 \\
& Short-term aged & 799.52 & 3.41 & 14.64 & 30.15 \\
CRMB-22 & Long-term aged & 799.50 & 5.82 & 11.53 & 20.28 \\
& Unaged & 1336.25 & 5.66 & 12.42 & 27.86 \\
& Short-term aged & 1331.96 & 5.49 & 19.86 & 28.94 \\
\hline
\end{tabular}

$$
\mathrm{AI}=\frac{J_{\mathrm{nr}, 3.2 \mathrm{kPa} \text { unaged }}}{J_{\mathrm{nr}, 3.2 \mathrm{kPa} \text { aged }}}
$$

Based on the AI values in Table 4, it is observed that at both short-term and long-term aging conditions, CRMB with higher CRM contents have lower AI values comparing to the neat bitumen, indicating less susceptible to aging effect. These findings coincide with the observations from FTIR results.

\subsection{Chemo-mechanics of aging}

As a result of the chemical changes of bitumen during aging, the mechanical properties of aged bitumen change as well. In previous studies, efforts have been made to correlate the oxidation products, mainly ketone and sulfoxide, with the mechanical parameters of bitumen, e.g., softening point, viscosity, complex shear modulus, phase angle, etc. [34, 35]. This socalled chemo-mechanics correlation will be beneficial to understand the dependence of mechanical properties of binders on their chemical composition. While ketone formation is well correlated to asphaltene formation on oxidation, sulfoxide formation does not contribute to asphaltene formation because sulfoxide derived from the oxidation of sulfides are less polar than asphaltene [1]. Asphaltenes have been proven to be primarily responsible for the viscosity increase (stiffening effect) on aging. Petersen et al. [6] reported that the alcohols, which are formed concurrently with the sulfoxides from the same hydroperoxide precursors as the ketones, have a similar effect on bitumen viscosity increase as do the ketones. This dual oxidation mechanism (formation of ketone and sulfoxide) contributes to the age hardening of bitumen. The sum of carbonyl index and sulfoxide index was used as the combined chemical aging index of bitumen after aging [36]. It is noteworthy that although aromaticity index of a binder is closely related to its mechanical properties [37], the relationship between aromaticity level and aging state is not well-defined as the carbonyl or sulfoxide index [8]. Therefore, the correlation was not done between aromaticity and mechanical parameters. In the presented study in this paper, six mechanical parameters, namely non-recoverable creep compliance and percent recovery at $3.2 \mathrm{kPa}$ from MSCR tests, $\mathrm{R}$ index and crossover frequency from master curves, rutting factor and G-R parameter, were correlated with the combined chemical aging index through statistical analysis in Fig. 7. Among all the mechanical parameters, $J_{\mathrm{nr}}$ gives the best correlation with the combined chemical aging index in terms of both short-term and long-term aging. The percent recovery and $G^{*} / \sin \delta$ show better 
Table 4 Summary of MSCR test results and $J_{\mathrm{nr}}$ based aging indices of binders at different aging states

\begin{tabular}{|c|c|c|c|c|c|c|}
\hline \multirow[t]{2}{*}{ Sample code } & \multirow[t]{2}{*}{ Aging condition } & \multicolumn{2}{|c|}{$J_{\mathrm{nr}}(1 / \mathrm{kPa})$} & \multicolumn{2}{|c|}{ Percent recovery $(\%)$} & \multirow[t]{2}{*}{ Aging index } \\
\hline & & $0.1 \mathrm{kPa}$ & $3.2 \mathrm{kPa}$ & $0.1 \mathrm{kPa}$ & $3.2 \mathrm{kPa}$ & \\
\hline \multirow[t]{3}{*}{$70 / 100$} & Unaged & 7.568 & 8.271 & 0.000 & 0.000 & \\
\hline & Short-term aged & 3.489 & 3.938 & 1.550 & 0.000 & 2.100 \\
\hline & Long-term aged & 0.937 & 1.093 & 10.010 & 2.800 & 7.564 \\
\hline \multirow[t]{3}{*}{ CRMB-5 } & Unaged & 1.884 & 3.053 & 19.985 & 0.640 & \\
\hline & Short-term aged & 1.336 & 1.780 & 22.350 & 3.725 & 1.715 \\
\hline & Long-term aged & 0.403 & 0.605 & 40.210 & 18.010 & 5.044 \\
\hline \multirow[t]{3}{*}{ CRMB-10 } & Unaged & 0.733 & 1.433 & 41.580 & 8.040 & \\
\hline & Short-term aged & 0.466 & 0.914 & 48.120 & 15.468 & 1.569 \\
\hline & Long-term aged & 0.219 & 0.349 & 55.360 & 33.260 & 4.106 \\
\hline \multirow[t]{3}{*}{ CRMB-15 } & Unaged & 0.164 & 0.539 & 70.577 & 25.350 & \\
\hline & Short-term aged & 0.142 & 0.413 & 76.317 & 32.447 & 1.306 \\
\hline & Long-term aged & 0.140 & 0.327 & 76.339 & 38.790 & 1.647 \\
\hline \multirow[t]{3}{*}{ CRMB-22 } & unaged & 0.027 & 0.226 & 87.170 & 30.815 & \\
\hline & Short-term aged & 0.022 & 0.182 & 91.435 & 41.657 & 1.241 \\
\hline & long-term aged & 0.059 & 0.143 & 72.800 & 47.360 & 1.579 \\
\hline
\end{tabular}

correlations with the chemical aging index for longterm aging than short-term aging. However, the other three parameters did not correlate well with aging due to the insensitivity of these parameters to capture the aging effect on binders. It seems that mechanical parameters in the nonlinear viscoelastic region can better differentiate the CRMB binders before and after aging.

\section{Conclusions and recommendations}

This study investigated the effects of laboratory shortterm and long-term aging on the chemistry and rheology of CRMB. The following conclusions can be drawn based on the test results:

- The modified static oven aging of bitumen sample with a thickness of $1.25 \mathrm{~mm}$ at $163{ }^{\circ} \mathrm{C}$ for $2 \mathrm{~h}$ can be an alternative to the standard RTFO aging procedure. The oven aging can be used to create short-term aged CRMB binders in the laboratory without difficulty.

- During the aging process, the aliphaticity index of all binders decreased but the reduction was insignificant. The aromaticity index of neat bitumen increased with the aging extent, while the aromaticity of all the CRMB binders first decreased after the short-term aging then increased after long-term aging. Both carbonyl and sulfoxide indices for each binder increased during aging. However, CRMB binders produced less carbonyl and sulfoxide functional groups than neat bitumen did after aging. The decrease in the oxidation products was intensified with the increase of CRM content.

- Aging causes binder to become stiffer and alters the rheological properties of all binders, i.e., increase in complex modulus, decrease in phase angle, decrease in non-recoverable creep compliance and increase in recovery ability.

- The addition of CRM into bitumen improved the aging resistance as reflected by the lower carbonyl and sulfoxide indices as well as after aging the less changed rheological parameters of CRMB comparing to neat bitumen. CRMB with higher CRM content showed higher resistance against aging, and thus against stiffening and embrittlement.

- The non-recoverable creep compliance and percent recovery from MSCR tests show better correlations with the combined chemical aging index (sum of carbonyl and sulfoxide indices) than the parameters derived from the linear viscoelastic region do.

This study demonstrated that bitumen modified by crumb rubber shows improved aging resistance, which is beneficial for the long-term performance of 
Fig. 7 Correlation between chemical aging index from FTIR and rheological parameters of bitumen a non-recoverable creep compliance $\mathbf{b}$ percent recovery $\mathbf{c}$ rheological index d crossover frequency e rutting factor and $\mathbf{f} \mathrm{G}-\mathrm{R}$ parameter

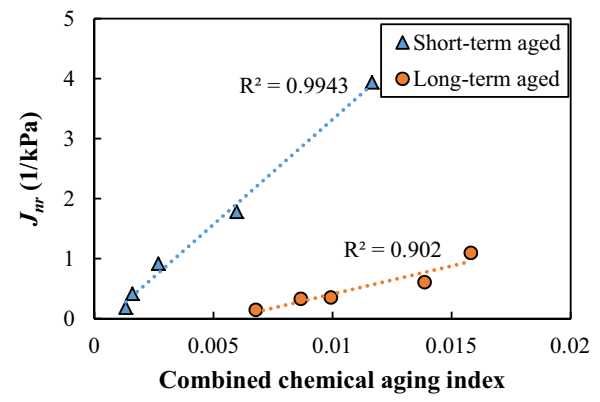

(a)

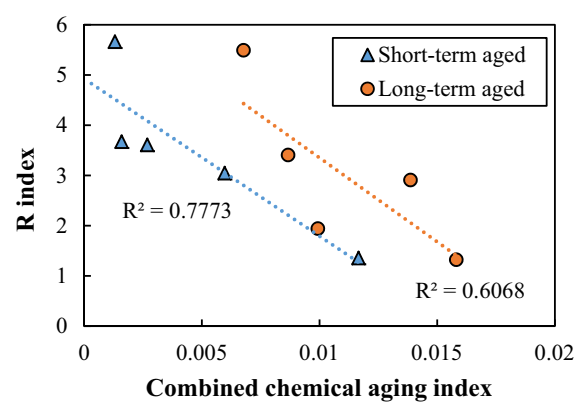

(c)

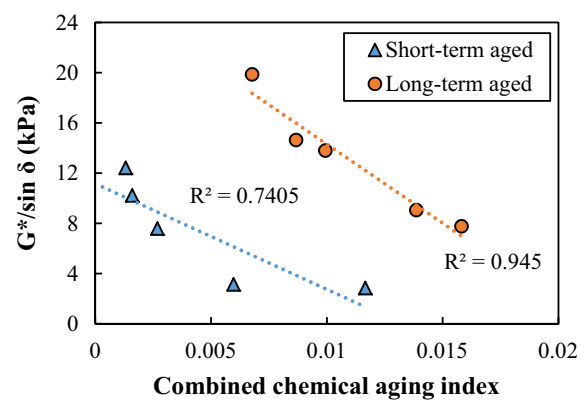

(e)

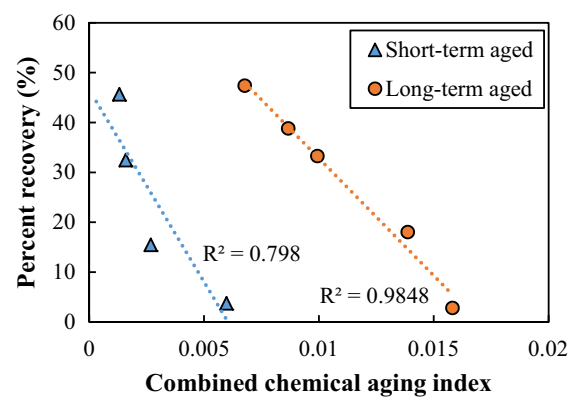

(b)

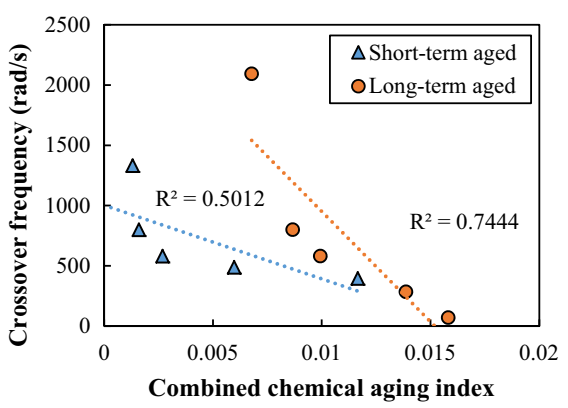

(d)

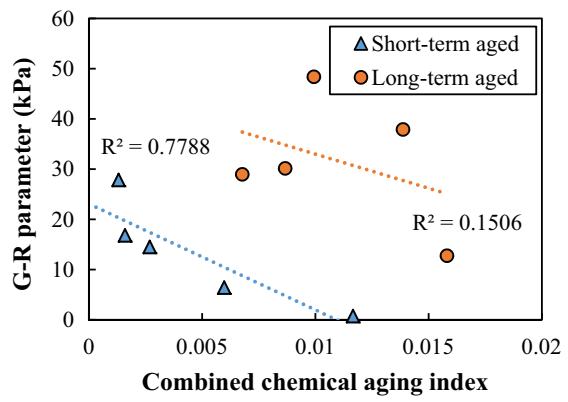

(f) rubberized asphalt pavement. Future research should be undertaken to investigate the aging effects on the chemo-physical properties of rubber polymer in bitumen and the possible rule of carbon black to have a better understanding of the aging mechanism of CRMB.

Acknowledgements The corresponding author would like to thank the financial support from China Scholarship Council. Special thanks go to Jirawat Buchagul for performing the DSR tests. The financial support of Khalifa University via the CIRA2018-115 research grant is also gratefully acknowledged.

\section{Compliance with ethical standards}

Conflict of interest The authors declare that there is no conflict of interest regarding the publication of this article.
Open Access This article is licensed under a Creative Commons Attribution 4.0 International License, which permits use, sharing, adaptation, distribution and reproduction in any medium or format, as long as you give appropriate credit to the original author(s) and the source, provide a link to the Creative Commons licence, and indicate if changes were made. The images or other third party material in this article are included in the article's Creative Commons licence, unless indicated otherwise in a credit line to the material. If material is not included in the article's Creative Commons licence and your intended use is not permitted by statutory regulation or exceeds the permitted use, you will need to obtain permission directly from the copyright holder. To view a copy of this licence, visit http://creativecommons.org/licenses/by/4.0/. 


\section{References}

1. Apostolidis P, Liu X, Kasbergen C, Scarpas AT (2017) Synthesis of asphalt binder aging and the state of the art of antiaging technologies. J Transp Res Board 2633:147-153. https://doi.org/10.3141/2633-17

2. Hofko B, Hospodka M (2016) Rolling thin film oven test and pressure aging vessel conditioning parameters. J Transp Res Board 2574:111-116. https://doi.org/10.3141/2574-12

3. Airey GD (2003) State of the art report on ageing test methods for bituminous pavement materials. Int J Pavement Eng 4(3):165-176. https://doi.org/10.1080/1029843042000198568

4. Lesueur D (2009) The colloidal structure of bitumen: consequences on the rheology and on the mechanisms of bitumen modification. Adv Coll Interface Sci 145(1-2):42-82. https://doi.org/10.1016/j.cis.2008.08.011

5. Lu X, Isacsson U (2002) Effect of ageing on bitumen chemistry and rheology. Constr Build Mater 16(1):15-22

6. Petersen JC, Glaser R (2011) Asphalt oxidation mechanisms and the role of oxidation products on age hardening revisited. Road Mater Pavement Des 12(4):795-819. https://doi. org/10.1080/14680629.2011.9713895

7. Jing R, Varveri A, Liu X, Scarpas A, Erkens S (2019) Laboratory and field aging effect on bitumen chemistry and rheology in porous asphalt mixture. J Transp Res Board. https://doi.org/10.1177/0361198119833362

8. Tarsi G, Varveri A, Lantieri C, Scarpas A, Sangiorgi C (2018) Effects of different aging methods on chemical and rheological properties of bitumen. J Mater Civ Eng. https:// doi.org/10.1061/(asce)mt.1943-5533.0002206

9. Rahbar-Rastegar R, Daniel JS, Dave EV (2018) Evaluation of viscoelastic and fracture properties of asphalt mixtures with long-term laboratory conditioning. J Transp Res Board 2672(28):503-513. https://doi.org/10.1177/0361198118795012

10. Wang H, Liu X, van de Ven M, Lu G, Erkens S, Skarpas A (2020) Fatigue performance of long-term aged crumb rubber modified bitumen containing warm-mix additives. Constr Build Mater. https://doi.org/10.1016/j.conbuildmat. 2019.117824

11. Wang H, Liu X, Apostolidis P, Scarpas T (2018) Review of warm mix rubberized asphalt concrete: towards a sustainable paving technology. J Clean Prod 177:302-314. https:// doi.org/10.1016/j.jclepro.2017.12.245

12. Liang M, Xin X, Fan W, Ren S, Shi J, Luo H (2017) Thermostability and aging performance of modified asphalt with crumb rubber activated by microwave and TOR. Mater Des 127:84-96. https://doi.org/10.1016/j.matdes.2017.04.060

13. Wang H, Liu X, Apostolidis P, Erkens S, Scarpas T (2019) Numerical investigation of rubber swelling in bitumen. Constr Build Mater 214:506-515. https://doi.org/10.1016/j. conbuildmat.2019.04.144

14. Abdelrahman MA, Carpenter SH (1999) Mechanism of the interaction of asphalt cement with crumb rubber modifier. J Transp Res Board 1661:106-113

15. Wang H, Liu X, Zhang H, Apostolidis P, Erkens S, Skarpas A (2020) Micromechanical modelling of complex shear modulus of crumb rubber modified bitumen. Mater Des. https://doi.org/10.1016/j.matdes.2019.108467

16. Ghavibazoo A, Abdelrahman M (2013) Composition analysis of crumb rubber during interaction with asphalt and effect on properties of binder. Int J Pavement Eng 14(5):517-530. https://doi.org/10.1080/10298436.2012.721548

17. Gawel I, Stepkowski R, Czechowski F (2006) Molecular interactions between rubber and asphalt. Ind Eng Chem Res 45(9):3044-3049. https://doi.org/10.1021/ie050905r

18. Cortizo MS, Larsen DO, Bianchetto H, Alessandrini JL (2004) Effect of the thermal degradation of SBS copolymers during the ageing of modified asphalts. Polym Degrad Stab 86(2):275-282. https://doi.org/10.1016/j.polymdegradstab. 2004.05.006

19. Wang H, Lu G, Feng S, Wen X, Yang J (2019) Characterization of bitumen modified with pyrolytic carbon black from scrap tires. Sustainability. https://doi.org/10.3390/ su11061631

20. Ouyang C, Wang SF, Zhang Y, Zhang YX (2006) Improving the aging resistance of styrene-butadiene-styrene tri-block copolymer modified asphalt by addition of antioxidants. Polym Degrad Stab 91(4):795-804. https:// doi.org/10.1016/j.polymdegradstab.2005.06.009

21. Wang H, Liu X, Zhang H, Apostolidis P, Scarpas T, Erkens $S$ (2018) Asphalt-rubber interaction and performance evaluation of rubberised asphalt binders containing non-foaming warm-mix additives. Road Mater Pavement Des. https:// doi.org/10.1080/14680629.2018.1561380

22. Erkens S, Porot L, Gläser R, Glover CJ (2016) Aging of bitumen and asphalt concrete: comparing state of the practice and ongoing developments in the United States and Europe. In: Paper presented at the transportation research board 95th annual meeting, Washington DC

23. Bahia HU, Zhai H, Range A (1998) Evaluation of stability, nature of modifier, and short-term aging of modified binders using new tests: LAST, PAT, and modified RTFO. Transportation Research Record 1638(1):64-71

24. Lamontagne J, Dumas P, Mouillet V, Kister J (2001) Comparison by Fourier transform infrared (FTIR) spectroscopy of different ageing techniques: application to road bitumens. Fuel 80(4):483-488. https://doi.org/10.1016/ S0016-2361(00)00121-6

25. Airey GD, Rahimzadeh B, Collop AC (2003) Viscoelastic linearity limits for bituminous materials. Mater Struct 36(10):643-647

26. Wang H, Liu X, Apostolidis P, Scarpas T (2018) Rheological behavior and its chemical interpretation of crumb rubber modified asphalt containing warm-mix additives. J Transp Res Board 2672(28):337-348. https://doi.org/10. 1177/0361198118781376

27. Bahia HU, Hanson DI, Zeng M, Zhai H, Khatri MA, Anderson RM (2001) Characterization of modified asphalt binders in superpave mix design. NCHRP Report 459. Transportation Research Board, Washington DC

28. Yan C, Xiao F, Huang W, Lv Q (2018) Critical matters in using attenuated total reflectance fourier transform infrared to characterize the polymer degradation in styrene-butadiene-styrene-modified asphalt binders. Polym Test 70:289-296. https://doi.org/10.1016/j.polymertesting.2018. 07.019

29. Petersen JC (2009) A review of the fundamentals of asphalt oxidation: chemical, physicochemical, physical property, and durability relationships. Transportation Research E-Circular, Washington, DC 
30. Nivitha MR, Prasad E, Krishnan JM (2015) Ageing in modified bitumen using FTIR spectroscopy. Int J Pavement Eng 17(7):565-577. https://doi.org/10.1080/10298436. 2015.1007230

31. Ghavibazoo A, Abdelrahman M, Ragab M (2015) Evaluation of oxidization of crumb rubber-modified asphalt during short-term aging. J Transp Res Board 2505:84-91. https:// doi.org/10.3141/2505-11

32. Anderson RM, King GN, Hanson DI, Blankenship PB (2011) Evaluation of the relationship between asphalt binder properties and non-load related cracking. J Assoc Asphalt Paving Technol 80:615-664

33. Mensching DJ, Rowe GM, Daniel JS, Bennert T (2015) Exploring low-temperature performance in black space. Road Mater Pavement Des 16(sup2):230-253. https://doi. org/10.1080/14680629.2015.1077015

34. Poulikakos LD, Wang D, Porot L, Hofko B (2019) Impact of asphalt aging temperature on chemo-mechanics. RSC Adv 9(21):11602-11613. https://doi.org/10.1039/c9ra00645a
35. Mullapudi RS, Deepika KG, Reddy KS (2019) Relationship between chemistry and mechanical properties of RAP binder blends. J Mater Civ Eng. https://doi.org/10.1061/(asce)mt. 1943-5533.0002769

36. Cavalli MC, Zaumanis M, Mazza E, Partl MN, Poulikakos LD (2018) Effect of ageing on the mechanical and chemical properties of binder from RAP treated with bio-based rejuvenators. Compos B Eng 141:174-181. https://doi.org/ 10.1016/j.compositesb.2017.12.060

37. Soenen H, Redelius P (2014) The effect of aromatic interactions on the elasticity of bituminous binders. Rheol Acta 53(9):741-754. https://doi.org/10.1007/s00397-014-0792-0

Publisher's Note Springer Nature remains neutral with regard to jurisdictional claims in published maps and institutional affiliations. 